\title{
Penilaian Kualitas Pelayanan Puskesmas dengan Model Donabedian: Studi Kasus Puskesmas di Kota Depok
}

\author{
Dian Ayubi*
}

\begin{abstract}
Abstrak
Perkembangan stuktur sosio-demografi penduduk dan infrastruktur Kota Depok yang pesat berpengaruh terhadap masalah kesehatan yang semakin kompleks. Pada era desentralisasi, Dinas Kesehatan Pemerintah Kota Depok dituntut memberikan pelayanan kesehatan masyarakat yang berkualitas antara lain melalui pelayanan kesehatan tingkat primer di puskesmas. Penelitian ini bertujuan menganalisis mutu pelayanan puskesmas dan hubungan struktur dan proses terhadap hasil pelayanan puskesmas, kepuasan pelanggan. Survey di rumah responden dilakukan pada bulan Maret 2004, dalam wilayah kerja enam puskesmas kecamatan di Kota Depok. Populasi adalah semua penduduk yang bermukim di wilayah kerja Puskesmas Kecamatan se-Kota Depok. Sampel adalah 300 rumah tangga yang tersebar di setiap kelurahan wilayah kerja masing-masing puskesmas kecamatan dengan responden ibu rumah tangga. Analisis dilakukan dengan pendekatan Structure, Process dan Outcome berdasarkan penilaian pasien. Penelitian ini menemukan nilai median atribut mutu struktur, proses dan kepuasan pelanggan adalah 75; 71,4 dan 75,0. Variasi pada dimensi struktur lebih lebar daripada dimensi proses. Secara bersama-sama, ada hubungan statistik yang bermakna antara struktur dan proses terhadap hasil di puskesmas kecamatan di Kota Depok. Aspek atribut struktur pelayanan puskesmas yang dinilai pelanggan perlu perbaikan adalah kelengkapan sarana, sedangkan untuk atribut proses adalah waktu tunggu pendaftaran.
\end{abstract}

Kata kunci : Model donabedian, kepuasan pelanggan

\begin{abstract}
Rapid growth of sociodemographic and infrastructure in Depok City has influenced the complexity of health problems. In the decentralization era, one of community health center function is to provide quality primary health care. The aim of this study is to assess quality of health services that was provided by subdistrict community health center based on Donabedian Model (Stucture Process Outcome). Survey was conducted in six sub-district community health centers. Data were collected using questionnaires. Respondents were interviewed in their home during March 2004. Samples covered 300 households in six areas. Median of stucture, process and outcome atributes of health services is $75,71.4$ and 75.0. Variation of stucture attribute is wider than process attribute. This study found there is a statistically significant correlation between structure and process attributes to outcome (patient satisfaction) of community health center services. In the structure attribute, equipment or facility aspect of community health center is needed to be improved while for process attribute, it is the aspect of waiting time in admission.
\end{abstract}

Key words : Donabedian model, patient satisfaction

*Departemen Pendidikan Kesehatan dan IImu Perilaku Fakultas Kesehatan Masyarakat Universitas Indonesia, Gd. D Lt. 1 FKM UI, Kampus Baru UI Depok 16424 (e-mail: dian_ayubi@yahoo.com) 
Menurut Organisasi Kesehatan Dunia (WHO), pelayanan kesehatan perlu dilakukan reformasi dengan melakukan reorganisasi sebagai asuhan primer. Dengan demikian, secara sosial fasilitas pelayanan kesehatan tersebut akan lebih sesuai dan lebih merespon berbagai tantangan yang abadi dalam masyarakat guna menghasilkan keluaran yang lebih baik. ${ }^{1}$ Tujuan penyelenggaraan upaya kesehatan dalam pembangunan kesehatan adalah untuk mencapai derajat kesehatan masyarakat yang optimal. ${ }^{2}$ Undang-Undang Kesehatan No. 23 Tahun 1994 Pasal 4 menyatakan bahwa setiap warga negara mempunyai hak yang sama dalam memperoleh derajat kesehatan yang optimal (bermutu). Untuk itu, pemerintah bertanggung jawab untuk melakukan berbagai upaya yang memungkinkan pencapaian peningkatan derajat kesehatan masyarakat secara optimal.

Untuk mencapai Indonesia Sehat pada tahun 2010, Departemen Kesehatan Republik Indonesia telah menetapkan berbagai strategi. Salah satu strategi tersebut adalah masyarakat Indonesia berkemampuan memperoleh/menjangkau pelayanan kesehatan yang bermutu secara merata, serta memiliki derajat kesehatan yang optimal. ${ }^{2}$ Ada beberapa alasan yang menjadi pertimbangan bahwa pelayanan kesehatan di Indonesia harus memperhatikan kualitas. Pertama, mutu pelayanan kesehatan merupakan hak masyarakat yang harus dipenuhi oleh pemerintah. Kedua, mutu pelayanan kesehatan dapat menjadi jaminan bagi pelanggan untuk mencapai hasil derajat kesehatan yang optimal. ${ }^{3}$ Puskesmas merupakan unit pelaksana pembangunan kesehatan di wilayah kecamatan yang mempunyai misi memelihara dan meningkatkan pelayanan kesehatan yang bermutu, merata dan terjangkau bagi masyarakat di sekitarnya. Di era desentralisasi, salah satu fungsi puskesmas yang penting adalah memberikan pelayanan kesehatan tingkat pertama (primary health care) yang merupakan fasilitas pelayanan di garis terdepan yang beroperasi pada tempat yang paling dekat dengan masyarakat. ${ }^{2}$

Dalam mendefinisikan mutu pelayanan kesehatan tersebut, Donabedian mengajukan suatu pendekatan konprehensif yang mencakup Structure, Process dan Outcome. Struktur adalah karakteristik pelayanan yang relatif stabil yang dimiliki oleh penyedia fasilitas pelayanan kesehatan. Komponen struktur meliputi: perlengkapan, sumber daya dan tatanan organisasi serta fasilitas fisik di lingkungan kerja. Komponen proses pada dasarnya adalah berbagai aktifitas yang merupakan interaksi antara penyedia fasilitas pelayanan kesehatan (misal dokter) dengan pasien yang menerima pelayanan kesehatan. Komponen outcome merujuk pada berbagai perubahan kondisi dan status kesehatan yang didapatkan oleh pasien setelah terakses dan menggunakan fasilitas pelayanan kesehatan. Komponen outcome tersebut antara lain meliputi morbiditas, mortalitas dan tingkat kepuasan pasien. ${ }^{4}$
Tabel 1. Karakteristik Sosial Demografi Responden

\begin{tabular}{|c|c|c|c|}
\hline Karakteristik & Katagori & $\mathbf{N}$ & $\%$ \\
\hline \multirow[t]{2}{*}{ Jenis Kelamin } & Perempuan & 279 & 93.0 \\
\hline & Laki-laki & 21 & 7.0 \\
\hline \multirow[t]{4}{*}{ Umur (tahun) } & $<25$ & 44 & 14.7 \\
\hline & $\leq 35$ & 129 & 43.0 \\
\hline & $\leq 45$ & 75 & 25.0 \\
\hline & $>45$ & 52 & 17.3 \\
\hline \multirow[t]{3}{*}{ Pekerjaan } & Ibu Rumah Tangga & 261 & 87.0 \\
\hline & Bekerja & 21 & 7.0 \\
\hline & Wiraswasta & 18 & 6.0 \\
\hline \multirow[t]{3}{*}{ Pendidikan } & $\leq \mathrm{SLTP}$ & 196 & 65.3 \\
\hline & SLTA & 86 & 28.7 \\
\hline & Perguruan Tinggi & 18 & 6.0 \\
\hline \multirow[t]{2}{*}{ Tabungan } & Ada & 112 & 37.3 \\
\hline & Tidak ada & 188 & 62.7 \\
\hline \multirow[t]{3}{*}{ Kepemilikan Rumah } & Milik sendiri & 209 & 69.7 \\
\hline & Menumpang & 40 & 13.3 \\
\hline & Sewa & 51 & 17.0 \\
\hline \multirow[t]{2}{*}{ Kunjungan ke Puskesmas } & Pernah & 225 & 75.0 \\
\hline & Tidak Pernah & 75 & 25.0 \\
\hline \multirow[t]{6}{*}{ Alasan ke Puskesmas } & Dekat rumah & 61 & 26.9 \\
\hline & Biaya murah & 117 & 51.5 \\
\hline & Pelayanan bermutu & 8 & 3.5 \\
\hline & Rujukan asuransi & 7 & 3.1 \\
\hline & Tidak ada pilihan & 1 & 0.4 \\
\hline & Lainnya & 33 & 14.6 \\
\hline
\end{tabular}

Tabel 2. Deskripsi Penilaian Mutu Struktur, Proses dan Hasil Puskesmas

\begin{tabular}{lccccc}
\hline Atribut Mutu & Median & St. Deviasi & Minimal & Maksimal & Range \\
\hline Struktur & 75.0 & 6.4 & 39.3 & 85.7 & 46.4 \\
Proses & 71.4 & 6.4 & 42.9 & 78.6 & 35.7 \\
Hasil (kepuasan) & 75.0 & 7.0 & 41.7 & 96.4 & 55.4 \\
\hline
\end{tabular}

Perkembangan struktur sosial demografi penduduk dan infrastruktur yang terjadi di Kota Depok memperlihatkan kecenderungan yang maju semakin pesat. Perkembangan tersebut berpengaruh terhadap permasalahan kesehatan masyarakat yang dirasakan semakin kompleks. Dengan demikian, Dinas Kesehatan Kota Depok semakin dituntut untuk memberikan pelayanan kesehatan masyarakat yang berkualitas dan terbaik bagi seluruh warga Kota Depok. Penelitian ini bertujuan menganalisis mutu pelayanan kesehatan yang diberikan oleh puskesmas dan hubungan komponen struktur dan komponen proses terhadap hasil yang dicapai oleh pelayanan kesehatan yang diberikan oleh puskesmas dalam wilayah Kota Depok pada tahun 2004.

\section{Metode}

Penelitian dengan desain penelitian kros seksional dengan metoda pengumpulan data survei ini dilakukan di 


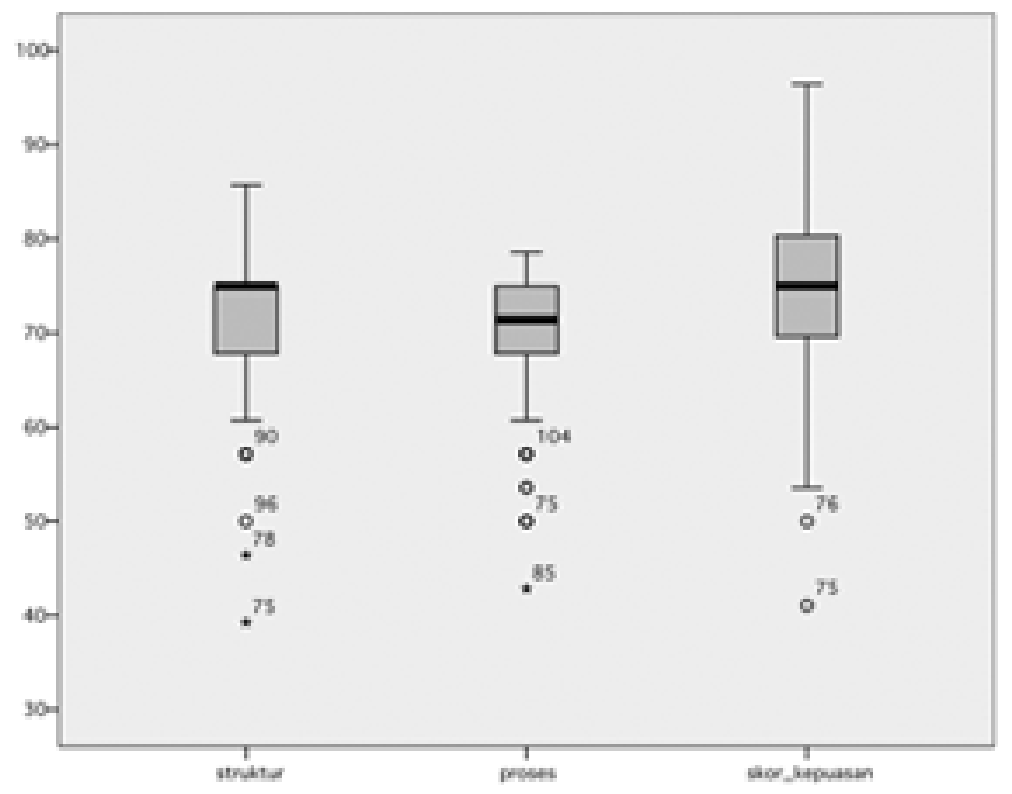

Gambar 1. Diagram Boxplot Aspek Struktur, Proses dan Hasil Pelayanan Puskesmas

enam wilayah puskesmas kecamatan di Kota Depok pada tahun 2004. Populasi adalah semua penduduk yang bermukim di wilayah kerja Puskesmas Kecamatan se Kota Depok. Jumlah sampel yang dikumpulkan adalah 300 rumah tangga yang tersebar di setiap kelurahan wilayah kerja masing-masing puskesmas kecamatan Kota Depok. Responden pada penelitian ini adalah ibu rumah tangga. Wawancara terstruktur dilakukan terhadap 300 responden ibu rumah tangga yang diambil dengan metode acak sistematik. Dari 300 responden yang diwawancarai tersebut terdapat 225 orang ibu rumah tangga yang pernah menggunakan pelayanan kesehatan yang diberikan oleh puskesmas kecamatan. Pengumpulan data dilakukan di rumah responden dengan menggunakan instrumen kuesioner. Seluruh pewawancara adalah mahasiswa FKM UI yang sedang melakukan kegiatan magang di Dinas Kesehatan Kota Depok. Sebelum dilakukan pengumpulan data, seluruh pewawancara tersebut mendapat pelatihan sebagai pewawancara. Struktur yang diamati pada penelitian ini mencakup jadwal buka pelayanan kesehatan, keahlian petugas, ketersediaan dan kemanjuran obat, kenyamanan dan kelengkapan sarana. Proses yang diamati mencakup waktu tunggu, penjelasan petugas, pemeriksaan, sikap petugas, kecepatan pelayanan dan ketanggapan petugas terhadap keluhan pelanggan. Hasil pelayanan yang diamati mencakup kepuasan pelanggan.

Pengukuran kualitas dilakukan berdasarkan persepsi responden. Sebagai sontoh, pertanyaan yang diberikan adalah "Seberapa cepat waktu tunggu pendaftaran?". Dengan pilihan jawaban "Sangat cepat", "cepat", "lambat" dan "sangat lambat". Setelah itu ditanyakan "Bagaimana perasaan responden terhadap waktu tunggu pendaftaran?”. Pilihan jawaban yang disediakan adalah "sangat puas", "puas", "tidak puas" dan "sangat tidak puas".

\section{Hasil}

Karakteristik Responden

Berdasarkan karakteristik sosial demografi responden, pada penelitian ini ditemukan sekitar 93\% jenis kelamin responden adalah perempuan, berumur 35-45 tahyn $(68 \%)$ dan sekitar $65,3 \%$ berpendidikan SMP atau lebih rendah. Sebagian besar pekerjaan responden $(87,0 \%)$ adalah ibu rumah tangga, mempunyai rumah sendiri $(69,7 \%)$. Alasan responden menggunakan fasilitas pelayanaan kesehatan puskesmas adalah biaya yang murah $(51,5 \%)$ (Lihat Tabel 1).

\section{Hubungan Struktur dan Proses terhadap Hasil}

Median untuk nilai struktur, proses dan hasil pada penelitian ini masing-masing adalah 75,0; 71,4 dan 75,0. Nilai tertinggi kepuasan adalah 96,4 dengan range 55,4. (Lihat Tabel 2).

Berdasarkan Tabel 2 dibuat diagram boxplot seperti dalam Gambar 1. Gambar ini memperlihatkan bahwa 
Tabel 3. Deskripsi Hubungan Struktur dan Proses terhadap Hasil Puskesmas

\begin{tabular}{llll}
\hline Atribut Mutu & Beta & Nilai $\mathbf{p}$ & R square \\
\hline Struktur & 0.425 & 0.001 & 0.43 \\
Proses & 0.411 & 0.001 & \\
\hline
\end{tabular}

Tabel 4. Kinerja Pelayanan Berdasarkan Dimensi Struktur

\begin{tabular}{lc}
\hline Butir Pelayanan & Nilai Rerata \\
\hline Jadwal Buka Pelayanan & 70.4 \\
Keahlian Petugas & 72.9 \\
Ketersediaan Obat & 78.4 \\
Kemanjuran Obat & 70.9 \\
Kebersihan Ruangan & 73.2 \\
Kenyamanan Ruangan & 71.4 \\
Kelengkapan Sarana & 68.2 \\
\hline
\end{tabular}

Tabel 5. Kinerja Pelayanan Berdasarkan Dimensi Proses

\begin{tabular}{lc}
\hline Butir Pelayanan & Nilai Rerata \\
\hline Waktu Tunggu Pendafaran & 63.4 \\
Penjelasan Petugas & 69.7 \\
Pemeriksaan oleh Petugas & 72.0 \\
Sikap Petugas & 71.8 \\
Kecepatan Pelayanan & 68.3 \\
Ketanggapan Petugas & 71.3 \\
\hline
\end{tabular}

range aspek kepuasan lebih besar daripada aspek struktur dan proses.

Struktur dan proses memperlihatkan hubungan yang secara statistik bermakna terhadap hasil puskesmas ketika nilai p kurang dari 0,05. Kemampuan model dalam menjelaskan variasi hasil adalah sebesar 33\% (Lihat Tabel 3).

Pada komponen struktur, responden memberikan nilai rerata 68,2 untuk kelengkapan sarana dan pada dimensi proses, responden memberikan nilai rerata 63 untuk waktu tunggu pendaftaran (Lihat Tabel 4 dan 5).

\section{Pembahasan}

Secara umum, responden penelitian adalah ibu rumah tangga dengan kisaran usia 31 - 36 tahun. Dengan demikian, responden pada penelitian ini umumnya adalah berasal dari keluarga muda yang sebagian besar menyatakan mempunyai tabungan sehingga secara sosial ekonomi mereka tergolong pada kelompok sosial ekonomi menengah ke bawah. Nilai kepuasan yang ditemukan pada penelitian ini sangat bervariasi yang berada pada kisaran nilai 41 hingga 96. Banyak faktor yang berpengaruh terhadap tingkat kepuasan pada pelayanan yang diberikan suatu fasilitas pelayanan kesehatan. Masyarakat yang berasal dari kelompok sosial ekonomi menengah ke bawah dan berpendidikan rendah cenderung tidak puas terhadap pelayanan kesehatan yang mereka terima. ${ }^{5}$ Dilihat dari nilai median dan nilai maksimal atribut struktur dan proses, penelitian ini menemukan bahwa kualitas atribut struktur pelayanan lebih baik daripada kualitas proses. Namun, range atau variasi nilai proses lebih sempit daripada nilai struktur. Variasi nilai proses yang lebih sempit menunjukkan kualitas proses yang lebih terstandarisasi walaupun nilai tengah masih berada pada angka 71.

Peningkatan kualitas menuntut penyedia pelayanan yang memahami variasi pelayanan. Variasi yang berlebihan menunjukkan kualitas yang belum baik. Leebov dan Ersoz, ${ }^{3}$ menjelaskan bahwa tujuan peningkatan keberkelanjutan adalah mengurangi dan mengendalikan variabilitas di dalam proses pelayanan untuk mencapai keluaran yang diinginkan. Upaya yang dilakukan untuk mengurangi variasi adalah dengan membuat prosedur operasi terstandarisasi. Aspek pelayanan dalam atribut struktur yang mendapat penilaian terendah adalah kelengkapan sarana, sedangkan dalam atribut proses adalah waktu tunggu pendaftaran. Situasi ini memang banyak ditemukan bahwa kelengkapan sarana fasilitas pelayanan kesehatan paling sering menjadi keluhan bagi masyarakat karena secara objektif dapat diidentifikasi. Waktu tunggu umumnya dirasakan sebagai masalah terutama ketika pasien yang banyak menumpuk di ruang tunggu sedangkan jumlah staf yang memberikan pelayanan terbatas.

Pada atribut struktur, terlihat bahwa ketersediaan obat memperoleh penilaian kinerja yang tertinggi dari responden. Namun, kemanjuran obat memperoleh nilai sedikit lebih rendah daripada ketersediaan obat. Hal ini menunjukkan bahwa berbagai obat yang diresepkan oleh dokter, umumnya dapat diperoleh di puskesmas, tetapi masyarakat kurang percaya terhadap kemanjuran obatobat tersebut. Pada atribut proses, butir pemeriksaan yang dilakukan oleh petugas merupakan butir pelayanan yang mendapat nilai tertinggi pada atribut tersebut. Tampaknya masyarakat memberikan kepercayaan yang tinggi terhadap kemampuan petugas pelayanan kesehatan dalam melakukan pemeriksaan kesehatan.

\section{Kesimpulan}

Jika melihat variabel pendidikan dan kepemilikan tabungan dapat disimpulkan bahwa secara sosial ekonomi responden pada penelitian ini berasal dari kelompok menengah ke bawah. Atribut kualitas proses pelayanan puskesmas ditemukan lebih baik daripada atribut struktur. Atribut struktur dan proses berhubungan secara bermakna terhadap atribut hasil pelayanan puskesmas. Aspek dalam atribut struktur pelayanan puskesmas yang menurut para pelanggan 
perlu mendapat perbaikan adalah kelengkapan sarana. Sedangkan, aspek atribut proses pelayanan puskesmas yang menurut pelanggan perlu diperbaiki adalah waktu tunggu pendaftaran.

\section{Saran}

Berdasarkan hasil temuan penelitian ini disarankan untuk melakukan advokasi ke Dinas Kesehatan Kota Depok dan Pemerintah Kota Depok untuk melengkapi berbagai sarana kesehatan yang tersedia di puskesmas. Selain itu, perlu membentuk tim peningkatan mutu di setiap puskesmas kecamatan untuk melakukan perbaikan mutu secara berkelanjutan. Tim ini beranggotakan staf puskesmas yang memiliki kemauan untuk melakukan perbaikan mutu mulai dari penggalian masalah hingga penerapan upaya perbaikan mutu.

\section{Ucapan Terima Kasih}

Penulis mengucapkan rasa terima kasih kepada dr. Rustono Pinangdjojo, MM, mantan Kepala Dinas
Kesehatan Kota Depok dan drg. Ernawati, MKes mantan Kepala Seksi Puskesmas Dinas Kesehatan Kota Depok atas kesempatan yang diberikan sebagai technical assistant Survei Kepuasan Masyarakat atas Pelayanan Puskesmas di Kota Depok Tahun 2004.

\section{Daftar Pustaka}

1. World Health Organization. Primary healthcare: now more than ever. Genewa: WHO; 2008.

2. Departemen Kesehatan RI. ARRIME: pedoman manajemen puskesmas. Jakarta: Departemen Kesehatan RI; 2002.

3. Leebov, Wendy dan Ersoz, Jean C. The health care manajer's guide to continuous quality improvement. Chicago: American Health Association; 1991.

4. Donabedian A. Explorations in quality assessment and monitoring volume 1 the definition of quality and approaches to its aassessment. Michigan: Health Administration Press; 1980.

5. Thiedke CC. We really know about patient satisfaction? [edisi Januari 2007]. The Family Practice Management. Diunduh dari: www.aafp.org/fpm. 